\title{
Comparison of Corner-Butt 45 (Cb-45) and Corner-Lap (Cl) joints in friction stir welding
}

\author{
Widia Setiawan ${ }^{1, *}$, Djarot B. Darmadi², Wahyono Suprapto², and Rudy Soenoko ${ }^{2}$ \\ ${ }^{1}$ Lecturer at Sekolah Vokasi University of Gadjah Mada, he is taking Doctorate at University of Brawijaya \\ ${ }^{2}$ Senior Reseacher at University of Brawijaya
}

\begin{abstract}
The $10 \mathrm{~mm}$ thick Aluminum 6061 plates have been corner joined using varied design and those were $45^{\circ}$ Corner Butt and Corner Lap Joints (CB-45 \& CL). Friction tool was hardened EMS 45. True experimental method was used with independent parameters is feed rate which varied at $10 \mathrm{~mm} / \mathrm{min}, 15$ $\mathrm{mm} / \mathrm{min}$ and $30 \mathrm{~mm} / \mathrm{min}$ respectively. Other parameter such as rotating speed was kept constant. Experiment results show that, $\mathrm{CB}-45$ yields better properties than $\mathrm{CL}$. The tensile strength of CB-45 reaches $163.7 \mathrm{MPa}$ for $10 \mathrm{~mm} / \mathrm{min}$ feed rate. Whilst CL produces joint with tensile strength equal $120 \mathrm{MPa}$ for equal parameters. Microstructure observation showed that CB- 45 produces fine and homogenous appearance of $\mathrm{MgO}$ compared to $\mathrm{CL}$. This phenomenon is caused by the pin of CB-45 joint which fully penetrates the nugget zone which is not found in CL design. This microstructure in turn promotes higher tensile strength of CB- 45 .
\end{abstract}

\section{Introduction}

Friction Stir Welding (FSW) offers some benefit that can overcome the drawback of fusion welding when applied to aluminum. Problems such as porosity, the existence of $\mathrm{Al}_{2} \mathrm{O}_{3}$ film, hot cracking and strength loss is exhibited in fusion welding beside others such as residual stress (Darmadi et al., 2014). Mainly the problem of fusion welding is caused by phase transformation, from liquid to solid states (Darmadi et al., 2016), which is not performed in FSW.

As it has been implicitly mention in previous paragraph, FSW is a solid phase joining technique on fabrication industry. Good quality single sided and double sided butt, "T", and lap joints. Invented in 1991, and was originally used to produce butt joints of aluminum alloys (Thomas et al., 1991).

The Friction Stir Welding (FSW) is a solid-state, hotshear joining process which a rotating tool with a shoulder and terminating in a threaded pin. It moves along the butt surfaces of two rigidly clamped plates placed on a backing plate as shown in Fig. 1.

The shoulder position is firm contact with the top surface of the work-piece. The heat generated by friction on the shoulder and a lesser extent on the pin surface, softens the material being welded. During FSW, heat is generated by friction between the tool and the work piece through via plastic deformation. The fraction of the plastic deformation energy is stored within the thermo mechanically processed region in the form defect densities increment (Nandan et al., 2008)

Friction stir welding (FSW) is a friction welding, requires no added ingredients. The heat generated from

\footnotetext{
${ }^{*}$ Corresponding author: widia_s@.ugm.ac.id
}

friction between probe and workpiece. Probe spin at a certain speed then placed on a connection that has gripped material. Friction of both objects generate heat 0.8 point liquid workpiece (Tang et al., 1998). Then the pin is pressed and moved in the direction of the weld line. Probe melting point and hardness are used in friction stir welding to be greater than the material being welded. Welding by the method of friction stir welding (FSW) is used for welding the same material (similar metal) or a material that is not the same (dissimilar metal) such as steel, stainless steel, aluminum with brass and possible to weld a combination of other materials which can not be welded by other welding method.

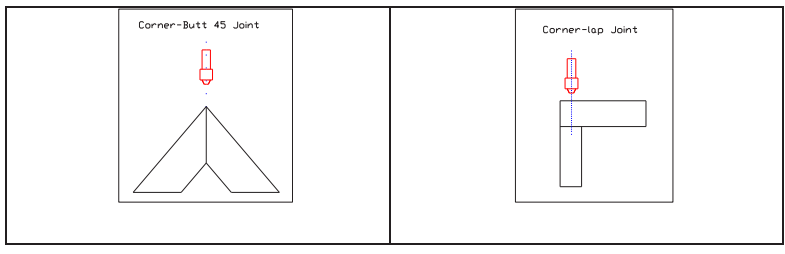

Fig 1. Corner-Butt 45 and Corner-Lap Joint on friction stir welding

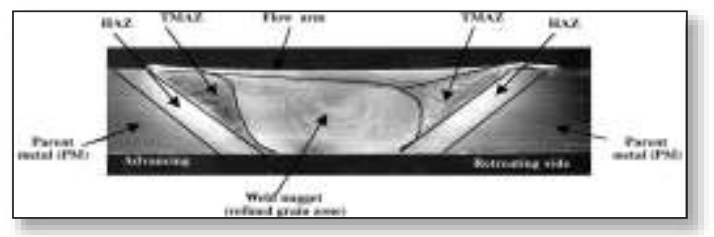

Fig 2. Heat zone pada friction stir welding (Mishra et al., 2007)

FSW process produces a typical microstructure. The 
resulting microstructure can be divided into four zones [4] as in figure 2.

The FSW has become an efficient option of welding method for the same or dissimilar aluminum alloys, especially those which are difficult or impossible to be welded by the conventional fusion welding without any hot crackings, blowholes or distortions (Kazi and Murr, 2001),( McNelley et al., 2008). The welding corner welds need to have a filled in order for the weld piece to achieve high enough rigidity. To be able to create this fillet additional material needs to be supplied into the weld. The additional material then needs to be mixed with the welds and shaped into a fillet. Because of the 90 degrees angle of the weld piece and the shaping of the fillet, it is not possible to have a rotating Shoulder. This is a stationary Shoulder is needed to be able to create a corner weld. When trying to create a corner weld with normal FSW without wire feeding the Shoulder will cut into the weld piece creating a non-rigid weld as seen Fig.3 (Alexander and Marcus, 2014).

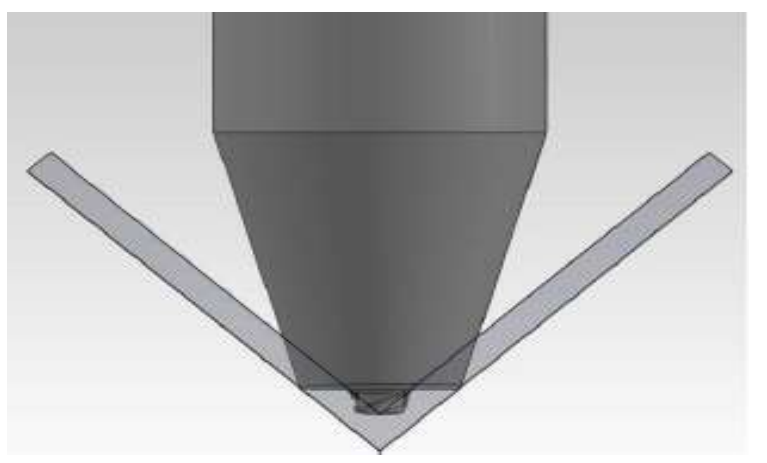

Fig 3. Corner jonit (Alexander and Marcus, 2014).

Friction Stir Welding is a new technique in the manufacturing industry, especially aluminum alloys. This non-consumable electrode technique makes use the heat generated by the rotating tool. Its deformation at the welding zone thereby affects the joint formation material into the solid state. The FSW has become an efficient option of welding method for the same or dissimilar aluminum alloys, especially those which are difficult or impossible to be welded by the conventional fusion welding without any hot crackings, blowholes or distortions (Padgett et al., 2003),( Ghosh et al., 2010).

In Journal Friction Stir Welded T-joint optimization [10]. One of the conclusions says at $1000 \mathrm{rpm}$, a depth of $3.90 \mathrm{~mm}$ diameter probe and the ratio of the shoulder/investigations 2.5 will be obtained an optimum connection.

Table 1. Level of the level parameters (Ana et al., 2013)

\begin{tabular}{|c|c|c|c|c|}
\hline Parameters & Unit & Level 1 & Level 2 & Lavel 3 \\
\hline A Tool rotutional speal & $\mathrm{rpm}$ & 490 & 1000 & 1500 \\
\hline B Welding speed & $\begin{array}{l}\mathrm{mm} / \\
\mathrm{min}\end{array}$ & 76 & 216 & 360 \\
\hline C Shoulder/probe diameters ratio (D/d) & $=$ & $2(12,6)$ & $25(15,6)$ & $3(18 / 6)$ \\
\hline D Probe depth & $\mathrm{mm}$ & 3.50 & 3.70 & $390^{\circ}$ \\
\hline
\end{tabular}

Conducted experiment with two combinations modes T-lap and T-Butt-lap joints, special clamping joint was used. As shown in fig 3. (Hou et al., 2013)

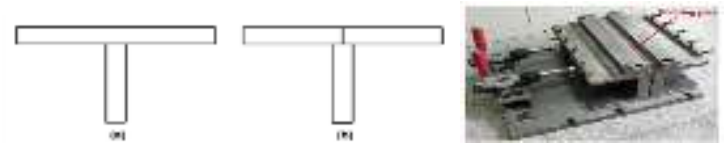

Fig 4. T-lap, T-Butt-lap joints, and special clamping fixture (Hou et al., 2013)

The same experiment with three combinations modes T-lap, T-butt-lap, and, T-double Butt joints is listed in fig.4 (Hou et al., 2013)

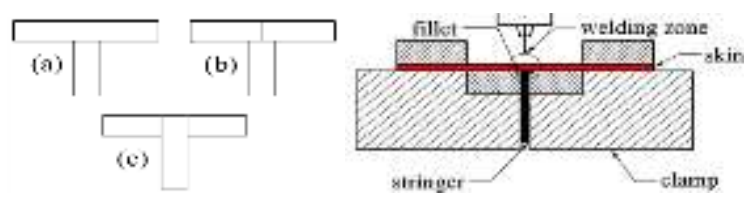

Fig 5. T-lap, T-butt-lap,T-double butt, and FSW process (Hou et al., 2013)

The Fig. 3 shows the effect of different rotational speeds on the recorded welding thermal cycles. The thermocouples were placed on the mid-plane of the plate on the advancing side (AS). It is $10 \mathrm{~mm}$ away from the weld center. It can be seen the peak temperature increases from 252 to $330{ }^{\circ} \mathrm{C}$ with the rotational speed increasing from $400 \mathrm{rpm}$ to $1000 \mathrm{rpm}$. Moreover, the typically elevated-temperature over $150{ }^{\circ} \mathrm{C}$ exposure time 150 chronological increases from 57 to $100 \mathrm{~s}$ as the rotational speed increases from $400 \mathrm{rpm}$ to $1000 \mathrm{rpm}$ (Wang et al., 2015).

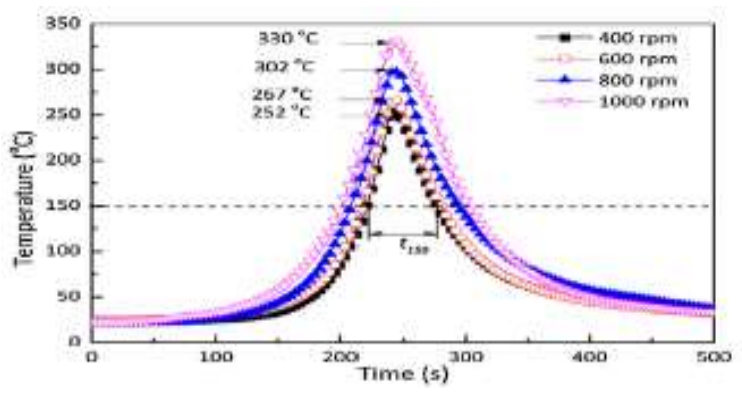

Fig 6. The welding thermal cycle of the joint produce (Wang et al., 2015).

\section{Experimental procedures}

In this study, the type 6061 aluminum material with dimensions of $150 \mathrm{~mm} \times 70 \mathrm{~mm} \times 10 \mathrm{~mm} .6061$ is a blend of pure aluminum with a Silicon ( $\mathrm{Si}$ ) and magnesium $(\mathrm{Mg})$. Tool / probe used in the research process are made from medium carbon steel material EMS 45 which has undergone a hardening process. The function of the tool / probe is to make the material into plastic and stir the plastic material in the connection area. 
Tabel 1. Chemical composition of 6061 aluminum alloy (wt.\%). ASM Metal Handbook, vol 9, 2004

\begin{tabular}{cccccccccc}
\hline Compositions & $\mathrm{Mg}$ & $\mathrm{Si}$ & $\mathrm{Cu}$ & $\mathrm{Mn}$ & $\mathrm{Fe}$ & $\mathrm{Cr}$ & $\mathrm{Ti}$ & $\mathrm{Zn}$ & $\mathrm{Al}$ \\
\hline Content & 1.5 & 1.8 & 0.25 & 0.086 & 0.18 & 0.1 & 0.192 & 0.01 & $\mathrm{Bal}$.
\end{tabular}
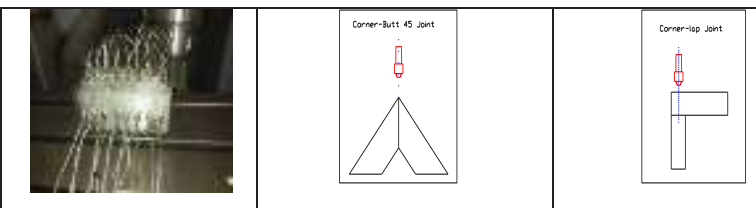

Fig 7. Installation of the workpiece in the jig fixture, thermocouple and design-Butt Joint Corner connection 45 (CB45) and Corner-Lap (CL)

Design probes that will be used in the process by the method of friction stir welding on 6061 aluminum material, thickness $10 \mathrm{~mm}$, the type of corner-Butt joint connection 45 (CB-45) and Corner-lap (CL) is as follows:

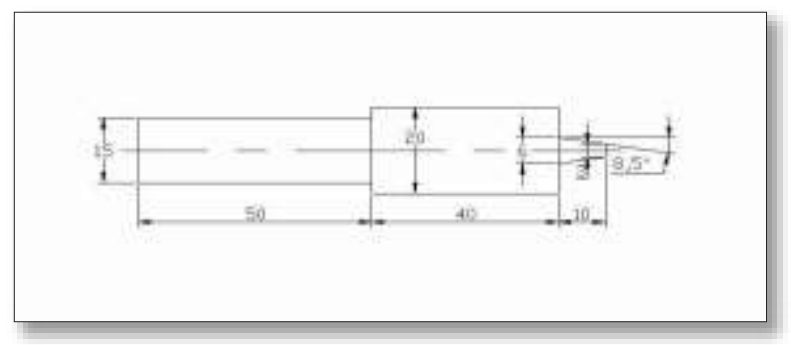

Fig 8. Design tool / probe

\section{Result and Discussion}

\subsection{Comparison Visually}

The result of the friction stir welding process of joining the 6061 design material connection CB- 45 and CL, use a $2000 \mathrm{rpm}$ spindle rotation and variation feedrate $10 \mathrm{~mm} /$ $\min , 15 \mathrm{~mm} / \min$ and $30 \mathrm{~mm} / \mathrm{min}$ is as follows:

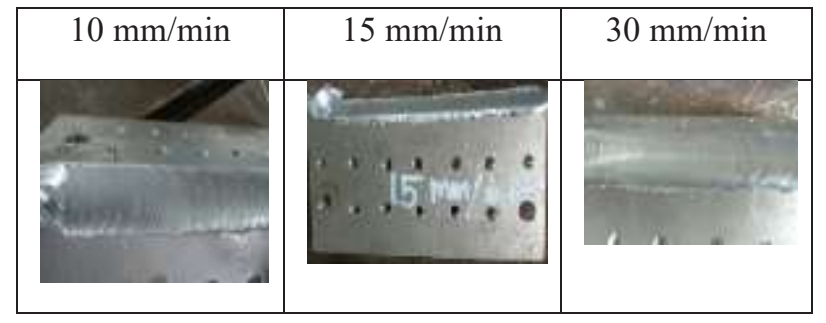

Fig 9. CB-45 Macro photos feedrate $10 \mathrm{~mm} / \mathrm{min}, 15 \mathrm{~mm} / \mathrm{min}$, and $30 \mathrm{~mm} / \mathrm{min} \mathrm{FSW}$

The first experiments carried out with feedrate 10 $\mathrm{mm} / \mathrm{min}$ and $2000 \mathrm{rpm}$ spindle rotation obtained good results seen visually, wherein the upper surface of the weld looks neat and almost all surfaces exposed to friction. This occurs because the time spent in a very long which is 15 minutes, resulting in plastic conditions which formed more homogeneous. Then the plastic material will be stirred by the PIN evenly and will cause the connection to be better. The plastic material that occurs will be stirred evenly by the PIN, making the joints tidy and flat for C-B 45 and C-L types. Si (silica) as an alloying element in aluminum 6061 also makes good flow, thus making the plastic material surface smooth for CB- 45 and CL types. See figures 9 and 10 on a feedrate of $10 \mathrm{~mm} / \mathrm{min}$.

In the second experiment performed with a feedrate of $15 \mathrm{~mm} / \mathrm{min}$ and spindle rotation of $2000 \mathrm{rpm}$, the results obtained were less good, compared to the first experiment with a feedrate of $10 \mathrm{~mm} /$ min visually seen. The welding results of the top surface look unkempt, because the temperature distribution is lower, then the time used for the connection process is shorter. So that plastic conditions are not well achieved (less homogeneous), this will result in the stirring PIN cannot do perfect mortar, resulting in rough macro photo surface conditions. This will cause poor connection quality. This will result in the stirring PIN is not able to do mortar material with less plastic conditions. Then it will cause poor connection quality for CB-45 and CL connection type at feedrate 15 $\mathrm{mm} / \mathrm{min}$. Can be seen in Fig. 9 and 10 feedrate $15 \mathrm{~mm} /$ $\min$.

In the third experiment conducted with a feedrate of $30 \mathrm{~mm} / \mathrm{min}$ and spindle rotation of $2000 \mathrm{rpm}$, obtained macro photo results look rough, because the plastic condition is clearly not achieved and not flat on each shift probe that occurred. Visually this illustrates the pastis condition of a material stirred by an imperfect pin, causing a rough surface texture of the surface. Because the time to warm up is less, about 5 minutes to make the connection process. Causing the resulting low temperature distribution. Will result in connection quality happening happened blowhole, porosity, Rough on the nugget area For the CB-45 connection type. (See fig. 9 at feedrate 30 $\mathrm{mm} / \mathrm{min}$ ). While for the CL connection type of heat is not reached, then plastic conditions are also not achieved. This results in cracks in joints along the line of connection. Can be seen fig. 10 at feedrate $30 \mathrm{~mm} / \mathrm{min}$.

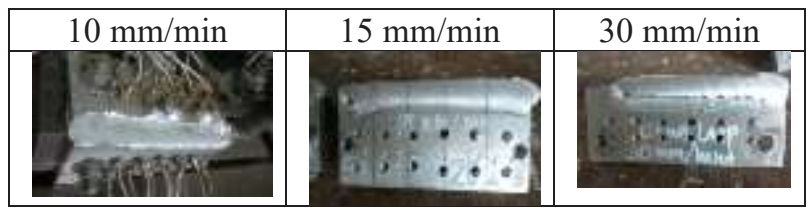

Fig 10. Macro photos CL feedrate $10 \mathrm{~mm} / \mathrm{min}, 15 \mathrm{~mm} / \mathrm{min}$, and $30 \mathrm{~mm} / \mathrm{min}$ FSW

\subsection{Weld Thermal Cycles}

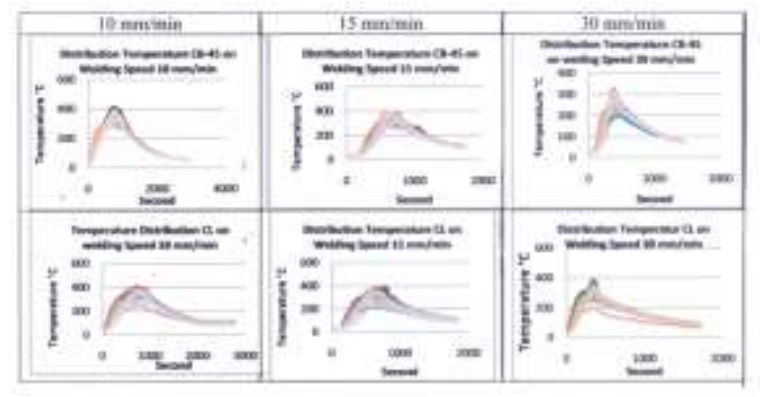

Fig 11. Distribution welding temperature of CB-45 and CL with feedrate $10 \mathrm{~mm} \mathrm{~min}, 15 \mathrm{~mm} / \mathrm{min}$, and $30 \mathrm{~mm} / \mathrm{min}$. 
Measurement of temperature distribution that happened at aluminum connection 6061 with friction stirs welding method using data logger. Then the time required for feedrate $10 \mathrm{~mm} / \mathrm{min}$ is 900 seconds, while the time required for feedrate $15 \mathrm{~mm} / \mathrm{min}$ is 600 seconds, and the time to feed rate $30 \mathrm{~mm} / \mathrm{min}$ is 300 seconds. The temperature graphs generated in the process are as follows:

Figure 11. shows six temperature measurements on the welding friction stir welding process. In the first graph, the temperature distribution is generated with peak temperature reaching $434{ }^{\circ} \mathrm{C}$ in 747 seconds. At this temperature plastic material will be easily achieved. So the PIN will stir the plastic material perfectly. This will cause the connection quality to occur either, not Blowhole. Then visually macro photos more neat, smooth, with better connection quality. While at the third temperature graph distribution is $220{ }^{\circ} \mathrm{C}$ the temperature measurement occurs on the parent metal or $30 \mathrm{~mm}$ of the shoulder (fig. 9).

In the measurement of temperature distribution friction stir welding is done with feedrate $15 \mathrm{~mm} / \mathrm{min}$ position of CB-45 material Al 6061. In graph seen the first position indicates the distribution of temperature evenly in accordance with time reached. Peak temperature is 390 ${ }^{0} \mathrm{C}$ in 545 seconds. This is enough to make plastic material on aluminum, but plastic material that formed less homogeneous, so that PIN will be difficult to do the mortar plastic material. Poor connection quality, can also blowhole material as result of low heat produced. Due to the FSW process will be good when the temperature reached is 0.8 liquid temperature (Tang et al., 1998). (fig. 9 and fig. 10).

Figure 10. Before the process of grafting friction stir welding is done, the temperature of material $\mathrm{Al} 6061$ is 30 ${ }^{0} \mathrm{C}$. Then the probe/ tool begins to enter (plunge) and swipes the aluminum material 6061 (weld process), the temperature of the aluminum material 6061 began to rise slowly at about 500 seconds reaching the temperature of $311^{\circ} \mathrm{C}$. The time used is 5 minutes, the material length is $150 \mathrm{~mm}$, so the low temperature does not reach $0.8 \mathrm{Tm}$. This plastic condition is not achieved, so the probe PIN is not able to stir the semi-solid material. The results shows that defects is found, not fully melted interface, porosity and not good visual texture (Fig.10 and Fig. 11).

\subsection{Temperature Distribution.}
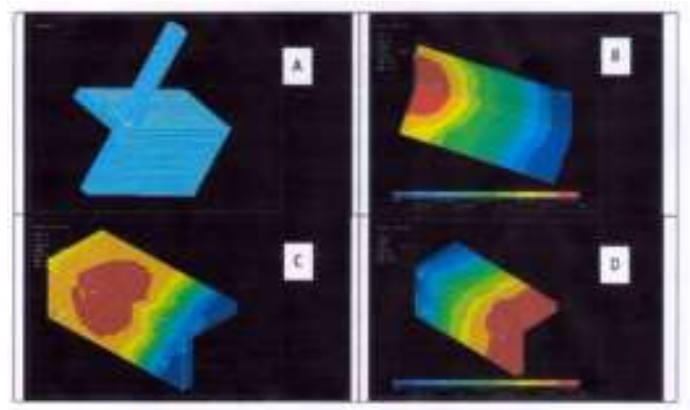

Fig 12. Mesh (A) and temperature distribution in 3 minutes (B), 8 minute $(\mathrm{C})$ and 15 minutes $(\mathrm{D})$
Fig. 12 explains In the process of friction for 15 minutes, the heat will be centered on the shoulder probe, temperature about $400{ }^{\circ} \mathrm{C}$, this occurs at a temperature difference thermocouple measurements. It can occur because of the position of the thermocouple within $20 \mathrm{~mm}$ from the center of the heat (Shoulder Probe). Fig. 11.A shows the heat that occurs at the time of 8 minutes, the temperature distribution almost all temperatures approaching $350{ }^{\circ} \mathrm{C}$. This position close to the perfect plastic material would be causing the connection quality is also good. FSW process 14 minutes later the temperature distribution at $400{ }^{0} \mathrm{C}$ nearly all plastic materials will be formed. So this will make the quality of the connection becomes stronger. (Fig 12.B)

\subsection{Micro Structure}

In Fig. 13, the $10 \mathrm{~mm} / \mathrm{min}$ feed rate shows a very clear line of connections, which indicates good connection quality (supported fig. 11). Then the microstructure that occurred was obtained by a homogeneous plastic condition compared to the microstructure at the other feed rate because the temperature reached at $10 \mathrm{~mm} / \mathrm{min}$ of high FSW process was $434{ }^{0} \mathrm{C}$. And the result of the plastic material PIN mix is more perfect, so it will obviously result in the mortar that occurs in the better microstructure photos, tensile stress will be high later.

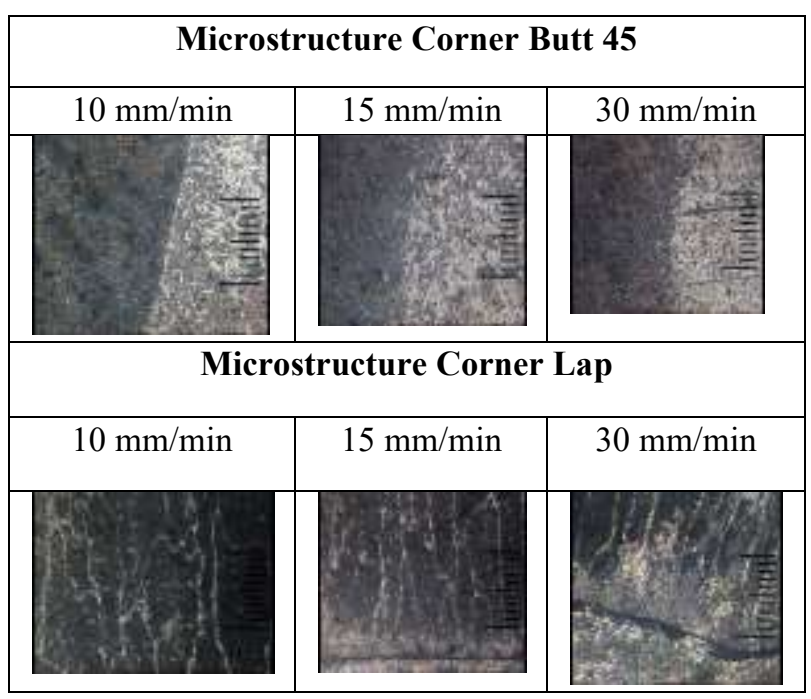

Fig 13. Microstructure corner butt 45 and corner lap Friction stir welding

The microstructure occurring is dominated by the $\beta$ $\mathrm{Mg}_{2} \mathrm{Si}$ phase, eventually forming a magnesium oxide $(\mathrm{MgO})$ compound at a low temperature of $150{ }^{\circ} \mathrm{C}$. With reduced Magnesium in $\mathrm{Al}-\mathrm{Mg}-\mathrm{Si}$ will result in reduced mechanical properties of aluminum 6061 . White color on Micro structure is a silica alloy ( $\alpha \mathrm{Al}$ phase) shows the mortar on the plastic material. The properties of silica provide a good flow of aluminum. Plastic material in direct contact with the tool/probe will form a finer homogeneous and black microstructure. Because at a temperature of $200{ }^{0} \mathrm{C}$, the magnesium-silicon alloy $\left(\mathrm{Mg}_{5} \mathrm{Si}_{6}\right)$ is more stable and does not change the crystal structure. But if formed above the temperature of $200{ }^{\circ} \mathrm{C}$ 
will form $\mathrm{Mg}_{5} \mathrm{Si}_{6}$ which dissolves dynamic recristallisation. This will decrease the mechanical properties and form a black precipitate. In the thermomechanically affected zone (TMAZ) region or area occurring on both sides of the stir zone, the structure looks coarser with a more dominant color of white. The black microstructure is the $\beta-\mathrm{Mg}_{2} \mathrm{Si}$ phase mixed with the $\mathrm{Fe}$ (iron) element of the probe/ tool while the white color is the $\alpha$-Al phase.

At Feed rate $15 \mathrm{~mm} / \mathrm{min}$, and $30 \mathrm{~mm} / \mathrm{min}$, the microstructure is formed brighter. This is as a result of high feed rate speed, $\mathrm{MgO}$ oxide compound that formed less due to the processing time of 10 minutes and 5 minutes, and oxygen that reacts to form a small magnesium oxide compound.

\subsection{Micro Vickers}

The hardness test is aimed to know the hardness of welding friction stir welding. This hardness testing is done by using micro Vickers method with 100 gf or 0.1 kgf indenter load.

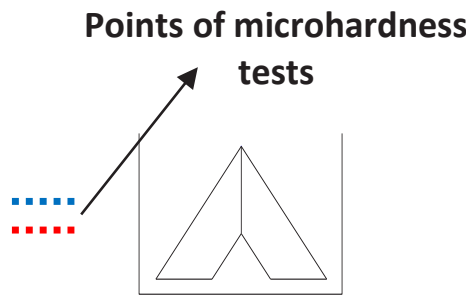

Fig 14. Points of microhardness vickers tests

Hardness testing is done on welding friction welding stirrer area with

Indent point as much as twelve points to the right and left of the center of the welded joint.

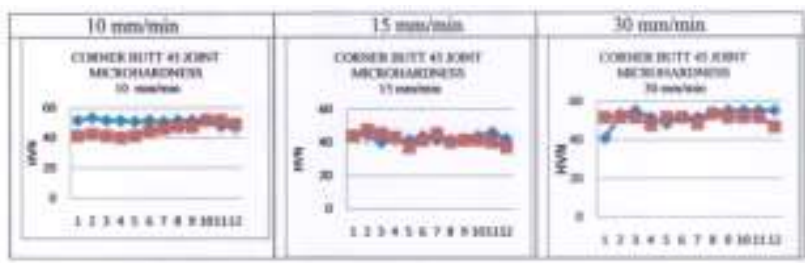

Fig 15. MicroVickers graph Corner Butt CB-45

From Figure 15,17 can be seen that a feed rate of 10 $\mathrm{mm} / \mathrm{min}$, and $15 \mathrm{~mm} / \mathrm{min}$ of mean hardness is higher than federate $30 \mathrm{~mm} / \mathrm{min}$. This can happen because the resulting temperature is low, then generated high temperature that is $306{ }^{\circ} \mathrm{C}$, and $243{ }^{\circ} \mathrm{C}$ this will cause the content of $\mathrm{Mg}$ (Magnesium) on Aluminum to form oxide compounds that $\mathrm{MgO}$ will increase the hardness, as well as mechanical properties. When viewed from the X-Ray test occurs Peak, it shows a lot of magnesium content to form oxide compounds. With the reduction of magnesium in alloys 6061 will cause the hardness to fall, but magnesium will bind to the oxide to form a magnesium oxide $(\mathrm{MgO})$ compound that causes the mechanical properties to rise. So from the theory and research data on the FSW process at high temperatures close to $0.8 \mathrm{TM}$ at
Al 6061 will result in increased hardness (Hasan et al. 2015).

Figure 19, XR-D shows the magnesium content to form the oxide compound $(\mathrm{MgO})$ more at a rate of 10 $\mathrm{mm} / \mathrm{min}$, this can happen because at a low $\mathrm{O} 2$ will bind more $\mathrm{Mg}$ about $150{ }^{\circ} \mathrm{C}$. Consequently, the reduction of $\mathrm{Mg}$ in Aluminum and binding to the oxide causes the mechanical properties to rise. At a higher of $15 \mathrm{~mm} / \mathrm{min}$ the oxide compound to form $\mathrm{MgO}$ will be lower.

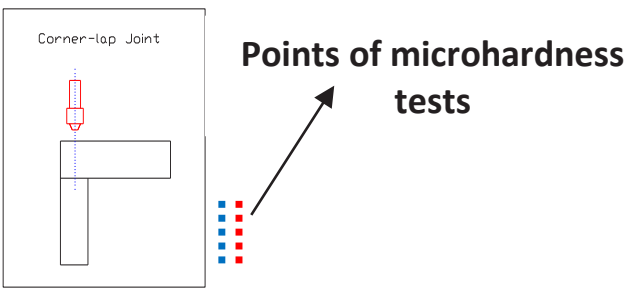

Fig 16. Points of microhardness vickers tests

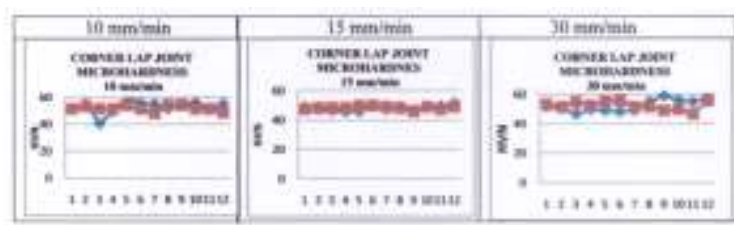

Fig 17. MicroVickers graph Corner Lap

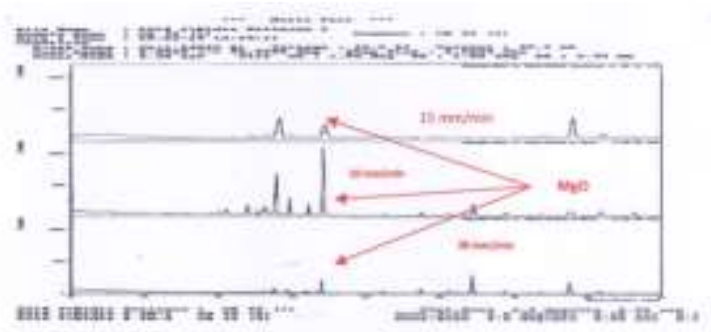

Fig 18. XR-D Corner-Butt 45 (CB-45) friction stir welding

\subsection{Tensile}

Tensile test of welding corner butt 45 corner and corner joint at aluminum 6061 friction stir welding method is used jig fixture fig. 19 as shown below:

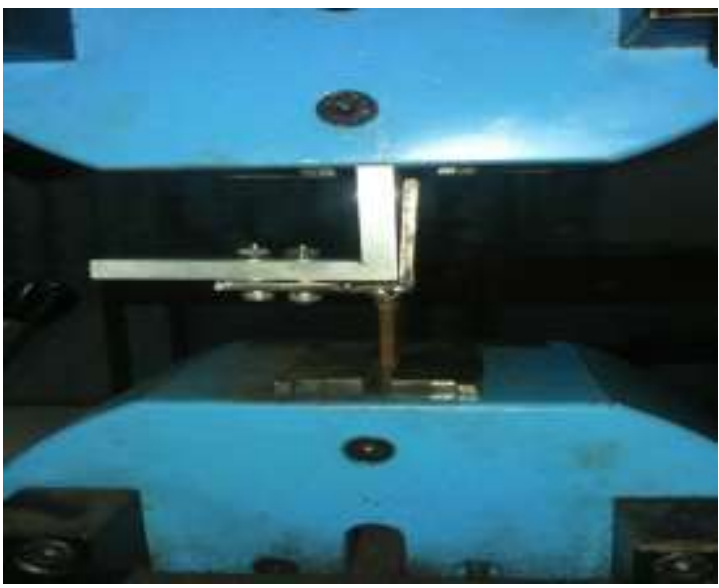

Fig 19. Tensile testing process with jig fixture 


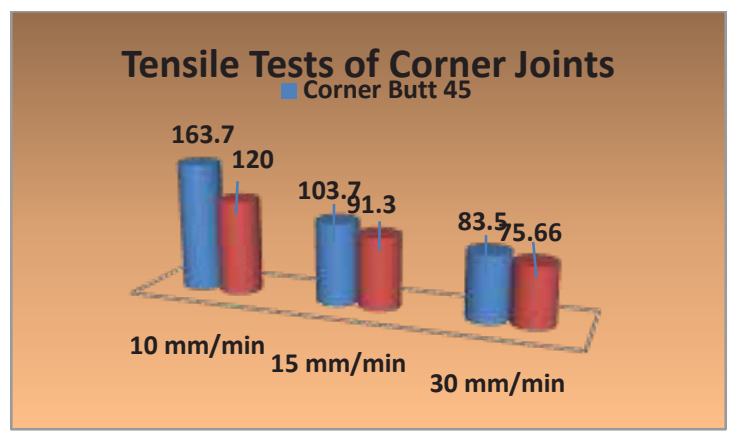

Fig 20. The average tensile stress graph of the FSW result

The highest tensile test value of 163.7 MPa at feedrate $10 \mathrm{~mm} / \mathrm{min}$ could happen:

At low Feedrate will be generated high temperature distribution, resulting in a more widespread homogeneous plastic area. This large plastic area will affect the Tensile Test results.

In the Corner Lap joint, the Pin probe height which is rubbing against the line of connection is not in full contact with the plate thickness, so that the probe pin-stirred material is only partially. ut this not-so-thick corner connection design will make the plastic material more homogeneous, so that the mortar will be better than federate $15 \mathrm{~mm} / \mathrm{min}$, or $30 \mathrm{~mm} / \mathrm{min}$, and the tensile strength of the material is better.

Corner Butt 45 joint, high pin probe will stir the plastic material as thick as the material to be joined. With this mortar the connection quality will be stronger than the Lap Corner. Also the magnesium bonded to the oxide will be more evenly thicker as material.

\section{Conclusions}

The Welding material of aluminum 6061 comparison corner Butt joint 45 and corner lap using friction stir welding method can be concluded as follows:

1. Corner butt 45 joint with feedrate $10 \mathrm{~mm} / \mathrm{min}$ has better result visually, micro structure, and temperature of $434{ }^{0} \mathrm{C}$. And the result of the connection has a smoother texture Compared to the corner lap joint.

2. From the SEM image, the microstructure, and the temparature distribution can be drawn to a red thread that is, the feedrate $10 \mathrm{~mm} / \mathrm{min}$ microstructure shows a good connection, supported by the SEM test, this is due to the high peak temperature distribution.

3. Welding with feedrate $10 \mathrm{~mm} / \mathrm{min}$, and $15 \mathrm{~mm} / \mathrm{min}$ average hardness higher, compared with $30 \mathrm{~mm} / \mathrm{min}$. Because Magnesium oxide is formed, and the peak temperature is high for corner butt 45 and corner lap.

4. The highest tensile stress is $154.67 \mathrm{MPa}$ at Feedrate $10 \mathrm{~mm} / \mathrm{min}$. Because the plastic material is more homogeneous, compared to feedrate $15 \mathrm{~mm} / \mathrm{min}$ or 30 $\mathrm{mm} / \mathrm{min}$.

\section{References}

1. Ana C.F. Silva, Daniel F.O. Braga, M.A.V. de Figueiredo b, P.M.G.P. Moreira,2013, Friction stir welded T-joints optimization, Instituto de Engenharia
Mecânica e Gestão Industrial (INEGI), R. Dr. Roberto Frias, 400 4200-465 Porto, Portugal Faculdade de Engenharia da Universidade do Porto (FEUP), R. Dr. Roberto Frias, s/n 4200-465 Porto, Portugal.

2. Beckham A., Sundstom M., 2014, Development of stationary for friction stir welding, Departement of product development, Chalmers University Of Technology, Gothenberg, Sweden.

3. Darmadi, D.B.; Kiet-Tieu, A. and Norrish, J. (2014), A validated thermo mechanical FEM model of beadon-plate welding, International Journal of Materials and Product Technology, vol. 48, nos. 1-4, pp. 146166.

4. Darmadi, D.B. (2016), Evaluation of the effects of melting phenomenon on the residual stress formation in ferritic pipeline multi pass girt-weld joints, International Journal of Engineering System Modeling and Simulation, vol. 48, no.3, pp. 205-217.

5. Dawood H. I. , Mohammed K., S. , Rahmat A., Uday M.B.,2015, The influence of the surface roughness on the microstructures and mechanical properties of 6061 aluminium alloy using friction stir welding, Universiti Malaysia Perlis, School of Materials Engineering, Taman Muhibah-Jejawi-Arau, 02600 Perlis, Malaysia UTM - Centre for Low Carbon Transport in cooperation with Imperial College London, Institute for Vehicle Systems and Engineering, Universiti Teknologi Malaysia, 81310 Skudai, Johor, Malaysia

6. Ghosh M. , Kumar K., Kailas S.V., Ray A.K., 2010, Optimization of friction stir welding parameters for dissimilar aluminum alloys, Materials Science and Technology Division, National Metallurgical Laboratory (CSIR), Jamshedpur 831 007, India Department of Mechanical Engineering, Indian Institute of Science, Bangalore 560 012, India

7. Hou X, Xinqi Yang, Lei Cui, Guang Zhou,2013, Influences of joint T-joints, Tianjin Key Laborat[ory of Advanced Joining Technology, School of Materials Science and Engineering, Tianjin University, Tianjin 300072, China.

8. Hou X, Xinqi Yang, Lei Cui, Guang Zhou Influences of joint geometry on defects and mechanical properties of friction stir welded AA6061-T4 Tjoints, Tianjin Key Laboratory of Advanced Joining Technology, School of Materials Science and Engineering, Tianjin University, Tianjin 300072, China,2013

9. Kazi SH, Murr LE. Complex flow phenomena associated with friction-stir welding of aluminum alloys. In: Mishra RS, et al., editors. Friction stir welding and processing, Warrendale (PA): TMS; 2001. p. 139-151.

10. McNelley TR, Swaminathan S, Su JQ. Recrystallization mechanisms during friction stir welding/processing of aluminum alloys. Scripta Mater 2008;58:349-54 
11. Mishra, Rajiv S dan Mahoney, Murray W. 2007. Friction Stir Welding and Processing. ASM Internasional.

12. Nandan R., DebRoy T., Bhadeshia H.K.D.H. Recent advances in friction-stir welding - Process, weldment structure and properties, Department of Materials Science and Engineering, Pennsylvania State University, University Park, PA 16802, USA Department of Materials Science and Metallurgy, University of Cambridge, Cambridge CB2 3QZ, UK, 2008.

13. Padgett PN, Paglia C, Buchheit RG. Characterization of corrosion behaviour in friction stir weld $\mathrm{Al}-\mathrm{Li}-\mathrm{Cu}$ AF/C458 Alloy. Friction stir welding and processing II. Warrendale (PA, USA): TMS; 2003.

14. Tang W., Guo X., McClure J.C., and, MURR. L.E., Metallurgicall, and Materials Engineering Departement, University of Texas at El Paso, El Paso TX 79968 USA, 1998
15. Thomas W.M., Nicholas E.D., Needham J.C., Murch M.G., P. Templesmith, C.J. Dawes, G.B Patent Application No. 9125978.8 (December 1991).

16. Wang F.F. , Li W.Y., Shen J., Hu S.Y., dos Santos J.F., Effect of tool rotational speed on the microstructure and mechanicalproperties of bobbin tool friction stir welding of Al-Li alloy, State Key Laboratory of Solidification Processing, Shaanxi Key Laboratory of FrictionWelding Technologies, Northwestern Polytechnical University, Xi'an 710072, Shaanxi, PR China HelmholtzZentrumGeesthacht, Institute of Materials Research, Materials Mechanics, Geesthacht 21502, Germany, 2015 